\title{
Isomer-specific effects of CLA on gene expression in human adipose tissue depending on PPAR 2 P I 2 A polymorphism: a double blind, randomized, controlled cross-over study
}

\author{
J Herrmann*1, D Rubin², R Häsler ${ }^{3}$, U Helwig², M Pfeuffer*1, A Auinger1, \\ C Laue ${ }^{4}$, P Winkler ${ }^{4}$, S Schreiber ${ }^{3}$, D Bell ${ }^{5}$ and J Schrezenmeir ${ }^{1}$
}

\begin{abstract}
Address: ${ }^{1}$ Max Rubner-Institut, Federal Research Institute of Nutrition and Food, Department of Physiology and Biochemistry of Nutrition, Karlsruhe and Kiel, Germany, ${ }^{2}$ UKSH Kiel, First Department of Medicine, Kiel, Germany, ${ }^{3}$ UKSH Kiel, Institute for Clinical Molecular Biology, Kiel, Germany, ${ }^{4}$ Center of Clinical Research, Tecura GmbH Medizin \& Biotechnik, Kiel, Germany and ${ }^{5}$ Nutrition \& Health - Global R \& D, Cognis GmbH, Monheim, Germany

Email: J Herrmann* - julia.herrmann@mri.bund.de; D Rubin - drubin@1med.uni-kiel.de; R Häsler - r.haesler@mucosa.de; U Helwig - helwig@internisten-ol.de; M Pfeuffer* - maria.pfeuffer@mri.bund.de; A Auinger - annegret.auinger@mri.bund.de; C Laue-c.laue@tecura.com; P Winkler - winkler-petra@gmx.de; S Schreiber - Doris.Bell@cognis.com; D Bell - juergen.schrezenmeir@gmx.de; J Schrezenmeir -s.schreiber@mucosa.de

* Corresponding authors
\end{abstract}

Published: 18 August 2009

Lipids in Health and Disease 2009, 8:35 doi:10.1186/1476-5IIX-8-35

This article is available from: http://www.lipidworld.com/content/8/I/35

(c) 2009 Herrmann et al; licensee BioMed Central Ltd.

This is an Open Access article distributed under the terms of the Creative Commons Attribution License (http://creativecommons.org/licenses/by/2.0), which permits unrestricted use, distribution, and reproduction in any medium, provided the original work is properly cited.
Received: 16 June 2009

Accepted: 18 August 2009

\begin{abstract}
Background: Peroxisome proliferator-activated receptor (PPAR) $\gamma$ is a key regulator in adipose tissue. The rare variant Prol $2 A$ la of PPAR $\gamma 2$ is associated with a decreased risk of insulin resistance. Being dietary PPAR $\gamma$ ligands, conjugated linoleic acids (CLAs) received considerable attention because of their effects on body composition, cancer, atherosclerosis, diabetes, obesity and inflammation, although some effects were only demonstrated in animal trials and the results in human studies were not always consistent. In the present study effects of CLA supplementation on genome wide gene expression in adipose tissue biopsies from I I Ala I2Ala and 23 Pro I 2Pro men were investigated. Subjects underwent four intervention periods $(4 \mathrm{wk})$ in a randomized double blind cross-over design receiving $4.25 \mathrm{~g} / \mathrm{d}$ of either cis- 9 , trans- I I CLA, trans-10,cis-12 CLA, I:I mixture of both isomers or a reference linoleic acid oil preparation. After each intervention biopsies were taken, whole genome expression microarrays were applied, and genes of interest were verified by realtime PCR.

Results: The following genes of lipid metabolism were regulated by CLA: LDLR, FASN, SCD, FADSI and UCP2 were induced, while ABCAI, CD36 and CA3 were repressed. Transcription factors PPAR $\gamma$, NFAT5, CREB5 and EBFI, the adipokine NAMPT, members of the insulin signaling cascade SORBSI and IGFI and IL6ST were repressed, while the adipokine THBSI and GLUT4 involved in insulin signaling were induced. Compared to trans-10,cis-12 CLA and the CLA mixture the cis-9, trans-I I CLA isomer exerted weaker effects. Only CD36 (-I.2 fold) and THBSI ( 1.5 fold) were regulated. The CLA effect on expression of PPAR $\gamma$ and leptin genes depends on the PPAR $\gamma 2$ genotype.
\end{abstract}

Conclusion: The data suggest that the isomer specific influence of CLA on glucose and lipid metabolism is genotype dependent and at least in part mediated by PPAR $\gamma$.

Trial registration: http://www.controlled-trials.com: ISRCTN9I I 88075 


\section{Introduction}

The term CLA describes a group of 18-carbon fatty acids with 2 conjugated double bonds. They are formed as a result of enzymatic hydrogenation of linoleic acid in ruminants and found in lipids of tissue and milk. Of the various isomers, cis-9, trans-11 (c9t11) CLA is most predominant in food. In CLA preparations C9t11 CLA and trans-10, cis-12 (t10c12) CLA are the prevailing isomers. CLAs received considerable attention because of their effect on body weight, muscle mass and glucose homeostasis $[1,2]$ in certain animal models. In humans evidence is less clear. CLA supplementation was shown to have significant favorable effects on body weight and fat mass $[3,4]$ while results on other risk markers are still conflicting. The findings showed great variability, which may be partly explained by the length of the studies and the dosage, but also due to differences in the isomer mixtures used for supplementation. Additionally, the genetic background of individuals may have contributed to the variability of the results.

The PPAR $\gamma 2$ gene is a member of the nuclear receptor super family and is highly expressed in adipose tissue [5]. Indeed, the receptor plays a critical role in adipocyte differentiation and regulates insulin sensitivity by transcriptionally activating adipocyte-specific genes involved in insulin signaling, glucose uptake, fatty acid uptake and lipid-storage. A single nucleotide polymorphism (SNP) in the PPAR $\gamma 2$ results in a proline to alanine substitution and has been associated with lower risk for type 2 diabetes, higher insulin sensitivity, but paradoxically weight gain [6]. The polymorphism of PPAR $\gamma 2$ was shown to affect metabolic responses to dietary fat $[7,8]$. CLAs are natural PPAR-ligands [9]. Only one report is available which provides data on the CLA influence on gene expression in human adipose tissue [10].

To our knowledge this is the first human study using a microarray based genome wide gene expression screening to evaluate isomer specific CLA effects in human adipose tissue. In this study we further investigated whether CLA effects depend on the Pro12Ala polymorphism.

\section{Methods \\ Subjects}

38 subjects (45-68 years old) were recruited from a population based cohort $(\mathrm{n}=1558)$ in Kiel (MICK, Metabolic Intervention Cohort Kiel) which has been previously described [11]. 15 male PPAR $\gamma 2$ Ala12Ala homozygous and 23 BMI-matched homozygous control subjects (PPAR 2 Pro12Pro) were included. Exclusion criteria were: metabolic or gastrointestinal diseases, drug therapy affecting gastrointestinal metabolism, and previously diagnosed diabetes according to WHO criteria (WHO, 2006). The intervention study was mono-centered and followed a randomized, placebo-controlled, double blind, cross over design. After written consent, 38 men randomly underwent four intervention periods, consuming soft gel capsules with either c9t11 CLA, t10c12 CLA, a commercially available mixture of both CLA isomers or placebo (linoleic acid from safflower oil) as free fatty acids; resulting in a total of $4.25 \mathrm{~g} / \mathrm{d}$ fatty acids, containing either $3.40 \mathrm{~g}$ of the individual isomers or CLA mixture active substance or $3.23 \mathrm{~g}$ linoleic acid. Study participants completed four intervention periods lasting 28 days each; separated by wash-out phases lasting 42 days. The study protocol was approved by the local ethics committee of the Christian-Albrechts-Universität (Kiel, Germany).

\section{Sampling}

After each intervention subcutaneous abdominal adipose tissue biopsies were performed under local anaesthesia by aspiration from the peri-umbilical area, through a Menghini-needle. Subcutaneous adipose tissue was immediately flash-frozen in liquid nitrogen for later analysis. BMI (body mass index), waist and hip circumference, blood pressure, plasma glucose and insulin, triacylglycerols, LDL-cholesterol HDL-cholesterol and HOMA-IR (homeostasis model assessment-insulin resistance) calculated as [(fasting insulin $\mu \mathrm{U} / \mathrm{ml} \times$ fasting glucose $\mathrm{mg} / \mathrm{dl}$ )/405] were assessed after each intervention. Multiple ANOVA was used to compare effects of the 4 dietary interventions.

\section{RNA}

RNA was extracted using Ambion kit according to the manufacturer's protocol for fatty tissue. RNA quality was verified by spectrophotometry (260:280 ratio) and by Bio analyzer (Agilent).

\section{Microarray}

Global gene expression was analyzed with microarray technology using the Affymetrix Human Genome U133 2.0 Plus according to the manufacturer's protocol and the Gene Chip Set, covering more than 54000 gene transcripts, corresponding to almost 22000 genes. Expression values were calculated using the robust multi-array average algorithm [12] and were statistically analyzed for differential gene expression adjusting all P-values for false discovery-rate correction. The positive and negative controls met the expected values (data not shown). Wilcoxon test followed by Benjamini Hochberg Correction as post hoc test for multiple testing was used to analyse significant differences compared to intervention with linoleic acid, and Westfall and Young permutation was used for cut off calculation [13]. Pathway members were analysed by Ingenuity Pathway Analysis ${ }^{\circledR}$ (Ingenuity Systems, http:/ /www.ingenuity.com) software. 


\section{RT-PCR}

Purified RNA was reverse transcribed using Applied Biosystems High Capacity cDNA Reverse Transcription Kit according to manufacturer's recommendations. Realtime PCR was performed using an ABI Prism 7900 HT Sequence Detection System with TaqMan ${ }^{\circledast}$ Low-Density Arrays, which is a 384-well micro-fluidic card pre-loaded with optimised probes and primers for selected genes. Relative quantification analysis was performed with $A B I$ Prism SDS 2.1.1 software. The endogenous control TAF10 (TAF10 RNA polymerase II) was used to normalize the differences in amounts of the cDNAs added. Normalized delta $(\Delta)$ cycle threshold $(\mathrm{CT})$ values were then subjected to evaluation of statistical significance ( $p<0.05$ ) of differential expression compared to control using the Wilcoxon test. Fold changes were calculated using the $\Delta \Delta \mathrm{CT}$ method, whereby linoleic acid intervention values were used as reference (control).

\section{Results}

37 out of 38 men completed the study. Data were based on 34 subjects; one dropped out because he fell ill and three subjects with PPAR 2 Pro12Pro SNP were excluded because they showed elevated fasting glucose levels according to the WHO criteria during most or all interventions. No significant changes in anthropometric characteristics and fasting values were detected after any intervention (Table 1).

From five PPAR 2 Ala12Ala subjects and five BMImatched Pro12Pro control subjects' microarray analyses were made after each intervention. The data have been deposited in NCBI's Gene Expression Omnibus and are accessible through GEO Series accession number GSE16615. The experiment showed the presence of approximately 12000 gene transcripts in subcutaneous adipose tissue, belonging to about 1200 different genes. According to Wilcoxon test at $\mathrm{p}<0.05,310$ genes were changed by the CLA preparations as compared to the control intervention. After Benjamini Hochberg Correction as post hoc test for multiple testing no intervention showed significant effects.

According to Westfall and Young permutation the cut off for a significant difference in gene expression between CLA and control intervention was set at +/- 1.51 fold change. Among the genes exceeding this limit only those were further evaluated that were detected on all microarrays, showed annotated gene symbols and resulted in no hypothetical proteins. Following these criteria 1020 gene transcripts were differently expressed after CLA intervention compared to the control (Figure 1).

The expression of 42 genes was verified by realtime PCR after all interventions in all subjects. The criteria for gene selection were as follows: they showed a strong difference in the expression after one or more CLA interventions compared to the control in microarray analysis, they showed a different expression between the two genotype groups after an intervention, they are a member of a regulated pathway (pathway analysis with Ingenuity Pathway Analyses $^{\mathrm{TM}}$ ) or they were previously described to be regulated by CLA.

Table 2 shows genes that were significantly regulated after CLA interventions $(p<0.05)$ or showed a strong tendency to be regulated (more than $+/-1.51$ fold change and $\mathrm{p} \leq$ $0.1)$.

\section{Discussion}

To elucidate the mechanism of different effects exerted by individual CLA isomers and the mixture of both CLA iso-

Table I: Anthropometric characteristics, fasting values of all subjects $(n=34)$ at the end of each intervention period.

\begin{tabular}{|c|c|c|c|c|c|}
\hline Preparation & linoleic acid & CLA MIX & cis-9,trans- I I CLA & trans-10,cis- 12 CLA & $\mathbf{P}$ \\
\hline Weight (kg) & $84.2( \pm 2.0)$ & $84.2( \pm 2.0)$ & $84.1( \pm 2.0)$ & $84.0( \pm 2.0)$ & 0.851 \\
\hline BMI $\left(\mathrm{kg} / \mathrm{m}^{2}\right)$ & $26.1( \pm 0.5)$ & $26.1( \pm 0.4)$ & $26.0( \pm 0.4)$ & $26.0( \pm 0.5)$ & 0.900 \\
\hline Waist $(\mathrm{cm})$ & $102.1( \pm 1.5)^{\mathrm{a}}$ & $102.1( \pm 1.6)^{a}$ & $102.3( \pm 1.5)^{\mathrm{a}}$ & $101.2( \pm 1.5) b$ & 0.072 \\
\hline $\mathrm{Hip}(\mathrm{cm})$ & $104.8( \pm 1.0)$ & $104.8( \pm 1.0)$ & $104.8( \pm 1.0)$ & $104.0( \pm 1.0)$ & 0.824 \\
\hline Waist/hip ratio & $0.97( \pm 0.01)$ & $0.97( \pm 0.01)$ & $0.98( \pm 0.01)$ & $0.97( \pm 0.01)$ & 0.645 \\
\hline Plasma glucose $(\mathrm{mg} / \mathrm{dl})$ & $96.5( \pm 1.4)$ & $98.2( \pm 1.5)$ & $97.5( \pm 1.5)$ & $96.5( \pm 1.4)$ & 0.487 \\
\hline HOMA-IR & $3.0( \pm 0.3)$ & $3.2( \pm 0.2)$ & $3.1( \pm 0.3)$ & $2.9( \pm 0.2)$ & 0.693 \\
\hline Triacylglycerols (mg/dl) & $127.0( \pm 10.1)$ & $119.1( \pm 8.9)$ & $124.4( \pm 10.8)$ & $124.7( \pm 10.6)$ & 0.787 \\
\hline Total cholesterol $(\mathrm{mg} / \mathrm{dl})$ & $223.9( \pm 7.3)$ & $225.3( \pm 6.8)$ & $223.6( \pm 7.2)$ & $226.5( \pm 6.8)$ & 0.783 \\
\hline LDL cholesterol (mg/dl) & $56.3( \pm 2.6)$ & $56.5( \pm 2.3)$ & $56.7( \pm 2.5)$ & $54.6( \pm 2.8)$ & 0.268 \\
\hline HDL cholesterol (mg/dl) & $145.4( \pm 6.0)$ & $|43|.( \pm 5.8)$ & $145.7( \pm 6.3)$ & $146.4( \pm 5.7)$ & 0.772 \\
\hline $\mathrm{SBP}(\mathrm{mmHg})$ & $127( \pm 3)$ & $127( \pm 3)$ & $128( \pm 3)$ & $126( \pm 2)$ & 0.901 \\
\hline $\mathrm{DBP}(\mathrm{mmHg})$ & $80( \pm 2)$ & $79( \pm 2)$ & $80( \pm 2)$ & $80( \pm 2)$ & 0.871 \\
\hline
\end{tabular}

Values are expressed as mean \pm SEM. CLA, conjugated linoleic acid; BMI, body mass index, DBP diastolic Blood pressure, SBP systolic blood pressure LDL low-density lipoprotein cholesterol, HDL high-density lipoprotein cholesterol, HOMA-IR; homeostasis model assessment-insulin resistance, intervention-dependent changes were compared using multiple ANOVA. 


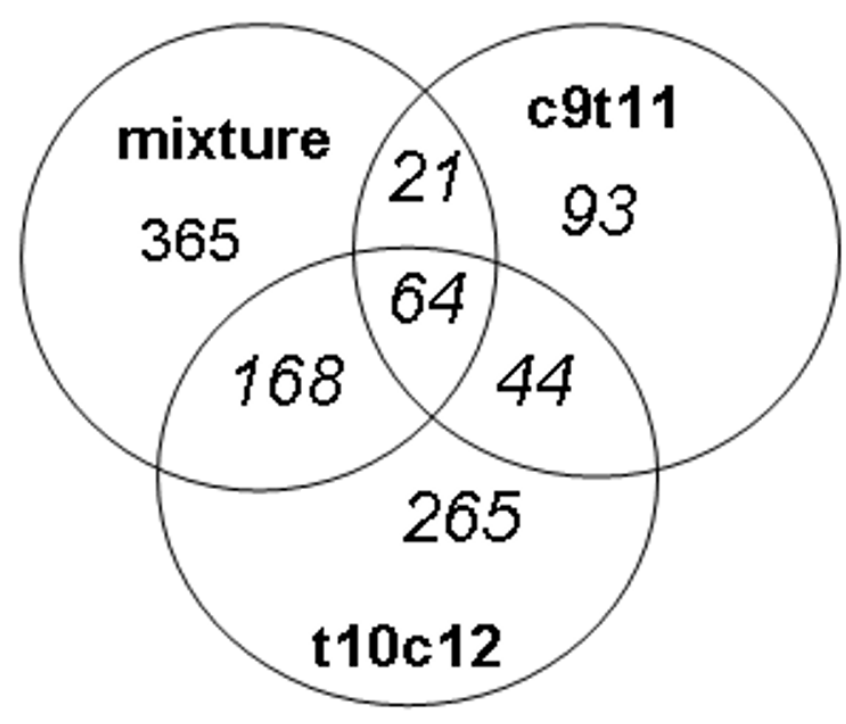

Figure I

Distribution of the gene transcripts $(n=1020)$ regulated more than +/- I.5 fold after the various interventions compared to linoleic acid control as assessed by whole genome gene expression microarray UI33 2.0 Plus GeneChip. Intersections show genes regulated by more than one treatment.

mers, a stepwise approach was applied. Following a hypothesis free approach by human genome wide gene expression screening, expression was verified by realtime PCR in those genes which showed measurable differences in expression compared to control intervention in the microarray experiment, which are members of relevant pathways or which were described in the literature as being regulated by CLA. Not all microarray results from a subgroup of five respectively ten persons could be verified for the whole study group by realtime PCR.

Microarray results indicated that single isomers and the CLA mixture of both isomers may modulate different genes. This was also confirmed by the results of realtime PCR (table 2). This may be due to the given structural differences between these isomers and due to the fact that more than one biochemical mechanism is supposedly involved in their specific effects.

\section{Fatty acid transport and metabolism}

Microarray analyses showed that ABCA9 (ATP-binding cassette, sub-family A, member 9) was much less expressed after CLA interventions in the 10 selected subjects. Verification for all 34 study subjects with realtime PCR confirmed this result for the CLA mixture and the t10c12 CLA intervention and showed genotype specific effects.
Little is known about the physiological function of ABCA9 especially in adipose tissue. ABCA9 is a member of the ABCA6-like transport subclass, which is regulated by cholesterol in an opposite direction than ABCA1 [14]. In human macrophages, ABCA9 mRNA is induced during monocyte differentiation and inhibited by cholesterol influx in human macrophages, indicating that ABCA9 is a cholesterol-responsive gene [15]. Lower expression in adipose tissue after CLA mixture and t10c12 CLA intervention (Table 2) may be due to high influx of cholesterol in adipocytes, however, total plasma cholesterol did not change after any CLA treatment (table 1).

The LDLR (LDL receptor) regulates plasma LDL cholesterol levels. Yu-Poth et al. showed that CLA mixture induces LDLR expression in the HepG2 hepatic cell line [16]. Others found the strongest enhancing effect on LDLR expression in mouse liver after t10c12 CLA administration compared to linoleic acid, whereas c9t11 CLA showed no effect [17]. We also found a higher expression after CLA mixture and $\mathrm{t} 10 \mathrm{c} 12$ CLA treatment (table 2). This effect was particularly found in Pro12Pro carriers. These results suggest that CLA may up-regulate LDLR gene expression to promote the clearance of LDL cholesterol from circulation. By that it may have inhibited ABCA9 expression (table 2). The observed effects of CLA on plasma lipids and particularly LDL-cholesterol in humans are conflicting. We found, however, no significant effects on plasma LDL or HDL cholesterol or triacylglycerol concentrations in our study (table 1).

CD36, another lipid transporter and scavenger receptor for oxidized LDL, was less expressed after c9t11 and t10c12 CLA treatment in all subjects. Lower expression of CD36 after t10c12 CLA incubation were also detected in mice 3T3-L1 cells [18]. Higher expression of LDLR and lower expressions levels of CD36 after t10c12 CLA treatment may be indicative of compensatory effects. Accordingly, LDLR-/- mice had higher CD36 expression [19]. Plasma glucose levels play an important role in the regulation of CD36 expression in adipose tissue [20]. Moreover, CD36 expression in subcutaneous adipose tissue was higher in type 2 diabetic subjects [21]. Ala12Ala carriers in particular showed significantly lower CD36 expression after the intervention with the single CLA isomers (table 2).

An explanation may be provided by an electrophoretic mobility shift assay experiment which showed that the PPAR 2 Ala-variant binds with lower affinity to an PPAR $\gamma$ responsive element than the Pro-variant [22]. A reduced transcription of specific PPAR $\gamma$ target genes was reported for cells over-expressing the Ala-variant compared to Provariant over-expressing cells [22]. 
Table 2: Fold change (median) of genes after 4 weeks intervention with a mixture of c9t l I and t l 0cl 2 CLA, c9t I I CLA, and t l 0cl 2 CLA compared to control (LA) according to realtime PCR verification.

\begin{tabular}{|c|c|c|c|c|c|c|c|c|c|c|}
\hline \multirow[b]{2}{*}{ Gene symbol [NCBI RefSeq] } & \multirow[b]{2}{*}{ all } & \multicolumn{2}{|l|}{ MIX } & \multicolumn{3}{|c|}{ C9TII CLA } & \multicolumn{3}{|c|}{ TIOCI2 CLA } & \\
\hline & & Pro & Ala & all & Pro & Ala & all & Pro & Ala & \\
\hline Fatty acid transport and metabolism & & & & & & & & & & PPAR $\gamma$ dependency \\
\hline ABCA9 [NM 080283.3] & $-1.3 *$ & $-1.3^{*}$ & & & & & $-1.4^{*}$ & & & $\mathrm{n} / \mathrm{a}$ \\
\hline LDLR [NM 000527.3] & $1.2 * *$ & $1.8 * *$ & & & & & $1.5 * *$ & $1.5^{\text {** }}$ & & $\uparrow[85]$ \\
\hline CD36 [NM 001001547.1$]$ & & & & $-1.2^{*}$ & & $-1.6 *$ & $-1.3^{*}$ & & $-1.2^{*}$ & $\uparrow[65,86]$ \\
\hline LIPE [NM 005357.2] & & & $1.96 t$ & & & & & & $1.8 \dagger$ & $\uparrow[23]$ \\
\hline CA3 $[N M \quad 005181.2]$ & & & & & & & $-2.0 * *$ & $-2.0 *$ & & $\mathrm{n} / \mathrm{a}$ \\
\hline FASN [NM 004104.4$]$ & & $1.5^{*}$ & & & & & $1.2 *$ & $1.4^{*}$ & & $\uparrow[87]$ \\
\hline SCD [NM 005063.4] & & & $1.3^{*}$ & & & & $1.5^{*}$ & & $1.9 *$ & $\uparrow[34,88]$ \\
\hline FADSI [NM 013402.3$]$ & $1.6 *$ & $1.6 *$ & & & & & & & & $\mathrm{n} / \mathrm{a}$ \\
\hline
\end{tabular}

\section{Transkription factors}

\begin{tabular}{|c|c|c|c|c|c|c|c|c|c|c|}
\hline PPARG [NM $|387| \mid .3]$ & & $-1.4^{* * a}$ & $1.3 \mathrm{~b}$ & & & & & & & \\
\hline NFAT5 [NM $|387| 3.2]$ & $-1.5^{*}$ & $-1.6^{*}$ & & & & & $-1.6 *$ & & $-1.9 \dagger$ & $\mathrm{n} / \mathrm{a}$ \\
\hline CREB5 [NM 182899.3] & & & & & & & $-1.5^{*}$ & & $-1.9 \dagger$ & $\mathrm{n} / \mathrm{a}$ \\
\hline EBFI [NM 024007.3] & & $-1.5 \dagger$ & & & & & & & & $\uparrow[89]$ \\
\hline \multicolumn{11}{|l|}{ Adipokines } \\
\hline ADIPOQ [NM 004797.29] & & & $1.6 \dagger$ & & & & & & $1.5 \dagger$ & $\uparrow[90,91]$ \\
\hline LEP [NM 000230.2] & & $-1.2 \mathrm{a}$ & $1.7+b$ & & & & & & & $\downarrow[92]$ \\
\hline NAMPT [NM 005746.2] & & & & & & & & & $-1.6^{*}$ & $=[62]$ \\
\hline THBSI [NM 003246.2] & & & & $1.5^{* *}$ & $1.3^{*}$ & $1.5 *$ & & & & $\downarrow[64] \uparrow[65]$ \\
\hline \multicolumn{11}{|l|}{ Insulin signaling } \\
\hline IGFI [NM 001111284.I] & & $-1.5 \dagger$ & & & & & $-1.2^{* *}$ & $-1.2 *$ & & $\downarrow[93]$ \\
\hline SLC2A4 [NM 001042.2$]$ & $1.3^{*}$ & & $1.5 \dagger$ & & & & & & & $\uparrow[94]$ \\
\hline SORBSI [NM_00I034954.I] & & $-1.2 *$ & & & & & & & & $\uparrow[74]$ \\
\hline PIK3RI [NM 181523.1$]$ & & $-1.6 \dagger$ & & & & & & & & $\uparrow[95]$ \\
\hline \multicolumn{11}{|l|}{ Others } \\
\hline HPGD [NM 000860.3$]$ & $-1.3^{* *}$ & & $-1.4^{* *}$ & & & & & & $-1.6^{*}$ & See text \\
\hline API5 [NM 006595.2] & & & & & & & $-1.3 \dagger$ & & $-1.5^{*}$ & $\mathrm{n} / \mathrm{a}$ \\
\hline CD74 [NM $001025 \mid 58.1]$ & & $1.2^{*}$ & & & & & & & & $\mathrm{n} / \mathrm{a}$ \\
\hline UCP2 [NM 003355.2] & $1.14^{*}$ & & & & & & & & $1.8 \dagger$ & $\uparrow[79]$ \\
\hline IL6ST [NM 175767.1$]$ & $-1.3^{*}$ & & & & & & $-1.5 \dagger$ & & $-1.8 \dagger$ & $\mathrm{n} / \mathrm{a}$ \\
\hline
\end{tabular}

Comparison of CLA interventions and control (Wilcoxon test): ${ }^{p} p<0.05$; **p $<0.001$; $\dagger$ marks values with a tendency $p \leq 0.1$ and more than $+/$ 1.5 fold change. Letters a and $b$ indicate significant differences $(p<0.05)$ between effects in PPAR 2 Prol2Pro (Pro; $n=23)$ and PPAR 2 Ala I 2Ala $(A l a ; n=I I)$ carriers after the CLA mixture supplementation (Mann-Whitney $U$ test).

LIPE (hormone sensitive lipase) is a key enzyme in mobilization of fatty acids from intracellular lipid stores and is a PPAR $\gamma$ target gene in human liver cells [23]. It was 1.96 fold more expressed after CLA mixture $(p=0.06)$ and 1.8 fold more after $110 \mathrm{c} 12$ CLA $(\mathrm{p}=0.09)$ treatment in the rare allele carriers. This does not support the findings from Nazare et al., who found a significantly lower expression of LIPE after a 14-week supplementation with CLA mixture in human adipose tissue [10], whereas lipoprotein lipase was not affected in their study. In contrast, in male Syrian Golden hamsters there was no effect on LIPE in adipose tissue after 3 weeks with a t10c12 CLA enriched diet [24].

CA3 (carbonic anhydrase 3) hydrates carbon dioxide to yield bicarbonate and carbohydrogen ion and has a variety of physiological functions. One is to provide bicarbonate ions necessary to convert acetyl-CoA into malonyl- 
CoA, the building block of fatty acids. CA3 is the most abundant protein of the rat adipose tissue and its expression decreased with obesity [25]. CA3 expression was decreased by leptin but increased by insulin in freshly isolated rat adipose cells, which suggests that the decrease in CA3 expression observed in obesity may be related to hyperleptinemia [26]. But in this study a significantly lower expression of CA3 was detected after t10c12 CLA compared to control intervention, while there was no change in leptin expression. These discrepant findings may be due to the known differences between humans and rodents [27]. The reduced expression of a key enzyme in fatty acid synthesis brought about by t10c12 CLA, however, fits the fat mass reduction observed in other studies [4].

FASN (fatty acid synthase) a multifunctional enzyme complex was significantly induced in carriers of the common allele after both CLA mixture and t10c12 CLA treatments and also in all subjects combined after t10c12 CLA treatment. FASN mRNA was up-regulated, leading to higher insulin concentrations in cultured human adipocytes [28]. Increased expression of FASN in adipose tissues was associated with excess fat accumulation and impaired insulin sensitivity [29].

SCD (stearoyl-CoA desaturase) is involved in fatty acid biosynthesis. The enzyme introduces a cis-double bond in the delta-9 position of certain saturated fatty acids and is the rate-limiting enzyme in the biosynthesis of monounsaturated fatty acids (MUFAs). Studies in animal models have shown that SCD is highly regulated by diet, but data in humans are limited [30]. As SCD is involved in the biosynthesis of MUFAs, namely palmitoleate (16:1) and oleate (18:1), the activity of SCD in adipocytes affects the fatty acid composition of cellular phospholipids, cholesterol esters and triacylglycerols [31]. In this study SCD expression was higher after t10c12 CLA supplementation in all subjects combined and for the rare PPAR $\gamma 2$ genotype both after CLA mixture and t10c12 CLA treatment. In contrast to this Brown et al. [32] found a lower expression in cultured human preadipocytes after incubation with t10c12 CLA compared to bovine serum albumin (BSA) control. Sjogren et al. showed that elevated SCD activity, measured as fatty acid desaturation index 18:1/18:0 in human adipose tissue, is closely coupled to the development of insulin resistance [33]. Another study however found no correlation between BMI, insulin sensitivity, triacylglycerol or plasma leptin levels and SCD expression in subcutaneous adipose tissue [34]. In the same study treatment with the PPAR $\gamma$ agonist pioglitazone increased the SCD expression and insulin sensitivity in subjects with impaired glucose tolerance [34]. SCD activity also increased the concentration of 16:1 and decreased the concentration of palmitate (16:0). Palmitate is a precursor of ceramides, which inhibit insulin-stimulated glucose transport and are involved in development of insulin resistance [35].

FADS1 (fatty acid desaturase 1) catalyzes endogenous synthesis of polyunsaturated fatty acids (PUFAs), including arachidonic acid and eicosanoids [36], which have, amongst others, proinflammatory and coagulatory effects. A higher FADS1 expression as observed in this study in Pro12Pro carriers and all subjects combined following the CLA mixture treatment may result in lower triacylglycerol and fasting insulin levels. Such a correlation was shown by Steffen et al. [37]. They found an inverse correlation between FADS1 activity measured as ratio of 20:4,n6/ $20: 3, \mathrm{n} 6$ and triacylglycerol as well as fasting insulin levels [37].

\section{Transcription factors}

Pro12Pro carriers showed a significantly lower PPAR $\gamma$ gene expression after CLA mixture treatment, whereas there was no change in Ala12Ala carriers. Thus the effect on PPAR $\gamma$ gene expression differed significantly between the two genotypes. This is the first time that genotype specific effects of CLA on PPAR gene expression in human adipose tissue were detected. This might explain some of the different results obtained in different human studies investigating the influence of CLA.

Brown et al. showed that c9t11 CLA increased and t10c12 CLA decreased the mRNA expression of PPAR $\gamma$ in primary human adiopocytes in vitro [32]. Stratifying for PPAR $\gamma$ isoforms Chung et al. found a suppression of PPAR $\gamma$ and $\operatorname{PPAR} \gamma 2$ at the mRNA and protein level in human cultured adipocytes after t10c12 CLA incubation [38]. Others, however, observed an increased expression of PPAR $\gamma$ in human adipose tissue after 14 weeks of a CLA mixture treatment [10]. As a key modulator in adipose tissue, $\operatorname{PPAR} \gamma$ controls several genes in lipid and glucose metabolism and is involved in the regulation of several genes affected by CLA treatment (table 2) $[23,34,49,62,64,65,74,79,85-95]$. The role of CLA as PPAR $\gamma$ ligand is not fully understood until now.

Thiazolidinediones (TZDs) - strong synthetic PPAR $\gamma$ agonists used in diabetes therapy to improve insulin sensitivity - induce weight gain (reviewed in [39]) whereas CLAs, natural PPAR $\gamma$ ligands, caused moderate weight loss in humans $[4,40]$ and in some studies reduced insulin sensitivity in an isomer specific way $[41,42]$.

This points out that there are several differing regulatory mechanisms of CLA and TZDs which are partly PPAR $\gamma$ independent. These results spur the question if CLA or single isomers are either PPAR $\gamma$ agonist or antagonist. In cultured human primary adipocytes t10c12 CLA antagonized 
PPAR $\gamma$ activity ligand-dependently [32,43], whereas Miller et al. showed that t10c12 CLA is a PPAR $\gamma$ agonist and that treatment of 3T3-L1 cells with t10c12 CLA decreases adiponectin through PPAR $\gamma$-dependent and PPAR $\gamma$-independent mechanisms [44].

Very recent studies on PPAR $\gamma$-DNA binding activity in human umbilical vein endothelial cells after treatment with the individual CLA isomers showed that the concentration determines whether CLA isomers exert inhibitory or a stimulatory effects in inflammatory and atherogenic processes, and that microenvironments also influence CLA effects [45]. The tissue dependent differences of action were also evident in mice; t10c12 CLA induced loss of adipose tissue but at the same time decreased fatty acid oxidation and increased fatty acid synthesis in liver [46].

Thus CLA effects depend on concentration, tissue, species, isomers, and once they are potential PPAR $\gamma$ ligands, maybe also on PPAR $\gamma$ polymorphisms.

NFAT5 (nuclear factor of activated T-cells 5) refers to the Rel family of transcription factors, which also comprises NFкB and NFATc. The exact pathways for NFAT5 regulation are largely unknown. NFAT5 expression was reduced following CLA mixture and t10c12 CLA treatment. High glucose concentrations increased binding activity of NFAT5 to osmotic response elements in both peripheral blood mononuclear cells and human mesangial cells, and silencing of NFAT5 reduced expression of aldose reductase (ADR) [47]. ADR is the first and rate-limiting enzyme of the polyol pathway where unused glucose is metabolized to sorbitol. ADR expression was associated with rapid development of diabetic microangiopathy in Japanese Type 2 diabetic patients [48]. However, in our microarray experiment ADR gene expression was not affected by treatments (data not shown).

CREB5 (cAMP responsive element binding protein 5) is another transcription factor which was less expressed after t10c12 CLA compared to control treatment in this study. Little is known about the function of CREB5. It is a member of the activating transcription factor 2 cAMP-binding protein family and is activated by a variety of kinases including protein kinase A and is involved in tumorigenesis of endocrine tissues and different forms of leukemia [49]. CREB5 was more expressed in omental adipose tissue biopsies of women with metabolic syndrome than in those of healthy women [50]. The lower expression levels after t10c12 CLA intervention is rated as a positive effect on metabolism.

The transcription factor EBF1 (early B-cell factor 1) is upregulated during adipocyte differentiation. In mouse adipose tissue Granlund et al. found no change after t10c12
CLA compared to BSA incubation [51]. This is in agreement with our realtime PCR results. We detected only a slight down regulation in the common genotype after CLA mixture treatment.

\section{Adipokines}

LEP (leptin) reduces fat depots via mediating the degradation of fatty acids by inducing uncoupling protein 2 (UCP2) and carnitine palmitoyltransferase-1 (CPT1), key enzymes of $\beta$ - oxidation [52], by decreasing acetyl-CoA carboxylase (ACC) [53] and by decreasing food intake [54]. Leptin, however, induces mitochondrial superoxide production and MCP1 (monocyte chemotactic protein 1) expression in endothelial cells [53], endothelial dysfunction [55] and CRP (C-reactive protein) expression [56]. Effects of CLA on leptin levels are conflicting. In Wistar rats CLA supplementation decreased serum leptin levels [57], while no differences were found after CLA supplementation in humans [10].

In this study none of the CLA supplements as compared to linoleic acid control affected gene expression, which confirms our microarray results. There was, however, a genotype specific difference after CLA mixture treatment as assessed by realtime PCR (Table 2); rare allele carriers had higher expression levels than PPAR $\gamma 2$ Pro12Pro carriers. Little is known about the functional impact of Pro12Ala polymorphism on leptin levels in humans. The lower leptin gene expression after CLA mixture treatment in subjects with the common genotype are in line with lower expression levels of PPAR $\gamma$ in this genotype. Same tendency was found for plasma leptin concentrations in this study (unpublished data).

Accordingly, ADIPOQ (adiponectin) gene expression, which depends on PPAR regulation, tended to be higher in rare allele carriers after CLA mixture and t10c12 CLA treatment (Table 2). While in young Finnish men Ala12Ala genotype of PPAR $\gamma 2$ was associated with elevated adiponectin level [58], the Ala12Ala allele was associated with lower serum adiponectin concentrations in Japanese men [59]. The same tendency was found in the MICK cohort [7]. These differing effects of PPAR $\gamma 2$ may be due to different dietary backgrounds. In the murine 3T3L1 cell line, t10c12 CLA compared to a non-stimulated control decreased adiponectin levels by PPAR $\gamma$-dependent and PPAR $\gamma$-independent mechanisms, whereas c9t11 CLA showed no effect [44]. In mice higher adiponectin levels were detected after treatment with pomegranate seed oil, a rich source of c9t11 CLA [60].

In rare allele carriers NAMPT (visfatin) was significantly less expressed after $\mathrm{t} 10 \mathrm{c} 12$ CLA supplementation compared to control. Plasma visfatin levels were increased in obese and insulin-resistant humans [61], and plasma lev- 
els and adipocyte gene expression were not affected by PPAR $\gamma$ ligands $[62,63]$.

Gene expression of the anti-angiogenic adipokine THBS1 (thrombospondin 1) was significantly higher after c9t11 CLA intervention according to our microarray and realtime PCR results. This adipokine is highly expressed in subcutaneous adipose tissue of obese and insulin-resistant subjects and is decreased by pioglitazone [64]. On the other hand, in endothelial cells THBS1 efficacy was improved by troglitazone through a PPAR $\gamma$ and CD36 dependent mechanism [65], which could result in an antiangiogenic action.

\section{Insulin signaling}

IGF1 (insulin-like growth factor 1) was less expressed after t10c12 CLA supplementation in PPAR $\gamma 2$ Pro12 Pro carriers and all subjects combined, and in PPAR 2 Pro 12 Pro carriers the expression was also slightly down regulated after CLA mixture treatment. These results are in line with findings in human colon cancer cells incubated with CLA mixture [66]. In adipose tissue IGF1 regulates adipogenesis, stimulates lipid oxidation, reduces protein oxidation, and enhances insulin sensitivity in humans [67]. Low serum IGF1 concentrations in humans were associated with lower visceral but not with lower subcutaneous or total fat mass [68] and IGF1 and blood glucose levels were inversely correlated in obesity before and during energy restriction [69]. These results suggest that lower expression levels of IGF1 might result in lower insulin sensitivity after t10c12 CLA treatment, which is in line with the lower CA3 and higher FASN expression observed in our study (Table 2).

The expression of GLUT4 (SLC2A4; solute carrier family 2, member 4), another key PPAR $\gamma 2$ target gene, was enhanced after CLA mixture supplementation compared to control, suggesting an improved insulin sensitivity. The effect was somewhat (not significantly) higher in rare allele carriers alone. In mice a c9t11 CLA-enriched diet increased adipose tissue plasma membrane GLUT4 and insulin receptor expression compared with the control linoleic acid-enriched diet [70]. While c9t11 CLA had no effect on GLUT4 expression in human preadipocytes [32], t10c12 CLA repressed GLUT4 in 3T3-L1 cells [18]. This may explain the induction of insulin resistance by the t10c12 CLA isomer found in some but not all human trials $[71,72]$. In our trial HOMA-IR did, however, not deteriorate during t10c12 CLA administration compared to the control (Table 1).

After CLA mixture intervention SORBS1 (sorbin and SH3 domain containing 1) gene expression was lower in microarray experiment; but realtime PCR confirmed this result only for the common PPAR $\gamma 2$ genotype. SORBS1 acts as an adaptor protein in the insulin-signaling pathway. It is partly dissociated from the insulin receptor complex and bound to c-Abl protein upon insulin stimulation [73]. TZDs, specific synthetic ligands of PPAR $\gamma$, can increase the expression of SORBS1 in adipose tissue [74]. Since SORBS1 is a PPAR $\gamma$ target gene, this result is in line with the lower expression of PPAR $\gamma$ after CLA mixture intervention in common allele carriers.

By alternative splicing of the PIK3R1 gene (phosphoinositide-3-kinase, regulatory subunit 1 alpha), the phosphatidylinositol 3-kinase (PI3K) regulatory subunit isoforms $\mathrm{p} 85 \alpha, \mathrm{p} 55 \alpha$ and $\mathrm{p} 50 \alpha$ are generated [75]. PI3K has been shown to regulate most of the insulin action [76]. Thus the lower gene expression level of PIK3R1 gene found after CLA mixture supplementation in the common allele carriers may have counteracted GLUT4 induction. Taken together the findings of counteracting actions in the insulin signaling pathway (IGF1, GLUT4, SORBS1, PIK3R1) (Table 2) may explain why CLA did not alter insulin sensitivity in our human trial (Table 1).

\section{Other regulated genes}

HPGD (hydroxyprostaglandin dehydrogenase 15(NAD)) catalyzes the oxidation reaction prostaglandin $\mathrm{E} 2$ (PGE2) to inactive 15-keto-PGE2 [77], which can act as a ligand of PPAR $\gamma$ to increase the recruitment of coactivators. Overexpression of HPGD increased PGE2-dependent activation of PPAR $\gamma$ in 3T3-L1 adipocytes [77]. In the present study there were lower expression levels after CLA mixture supplementation in the rare allele carriers and in all study subjects combined (Table 2). The Ala12Ala subgroup showed also significantly lower expression after t10c12 CLA treatment. Thus the repression of HPGD by CLA may have weakened PPAR $\gamma$ mediated effects in this study.

IL6ST (interleukin 6 signal transducer) is shared by many cytokines, including pro-inflammatory interleukin 6 (IL6). IL6 was shown to induce the plasminogen activator inhibitor-1 (PAI1) production in cultured human preadipocytes [78]. Rega et al. speculated that IL6, by up-regulating PAI1 in adipose tissue, might contribute to the increased cardiovascular risk of patients with obesity and insulin resistance syndrome due to the auto- or paracrine actions in human adipose tissue [78]. Thus the repression of IL6ST after CLA mixture and t10c12 CLA intervention might indicate counteraction to systemic inflammation.

UCP2, a mitochondrial uncoupling protein that decreases ATP synthesis coupled to energetic substrates oxidation expression, was significantly more expressed after CLA mixture intervention compared to the control. These results are consistent with those of Ryder et al. who found higher expression of UCP2 in mice adipose tissue after 
CLA mixture supplementation [2]. They also detected an up-regulation after c9t11 CLA treatment. TZDs can stimulate the expression of UCP2 gene, probably via PPAR gamma [79]. It was shown that regulation of adiponectin gene expression is also mediated specifically by mitochondrial UCP2 levels [80]. Higher levels of UCP2 were detected after $10 \mathrm{c} 12$ CLA in the PPAR $\gamma 2$ rare allele carriers (Table 2) and are in line with the fact that adiponectin levels were also higher in these subjects (data not shown).

CD74 showed a higher expression level after CLA mixture intervention (Table 2). Nothing is known about the function of CD74 in adipose tissue. In lymphocytes CD74 introduction leads to NFkB activation [81].

API5 (apoptosis inhibitor 5) gene expression was significant lower in rare allele carriers after t10c12 CLA treatment (Table 2). API5 was shown to suppress apoptosis [82]. Suppression of API5, therefore, might mediate the antitumor effects of CLA found in several studies [83].

\section{Conclusion}

CLA intake was shown to reduce BMI and body fat in overweight subjects in a number of studies [4]. Up to now, several human studies have been published but the effects on the risk markers of atherosclerosis and on traits of metabolic syndrome were rather inconsistent. Only few data are available on the effect of individual CLA isomers. This study provides novel information about the effects exerted by single CLA isomer intake on several genes as assessed by genome-wide gene expressions in human adipose tissue, prompting further insights in the mechanism of CLA action. Furthermore this is the first study in humans which focused on gene-nutrient interactions with respect to the PPAR $\gamma 2$ Pro12Ala SNP and CLA isomers.

Only two genes showed significant effects after c9t11 CLA intervention. This confirms the microarray results from Murphy et al [84], where there was no significant alteration in gene expression after the incubation of $\mathrm{CaCo} 2$ cells with c9t11 CLA, but plenty of effects after t10c12 CLA stimulation compared to linoleic acid control.

In summary the intervention with CLA mixture had the strongest effect on the key enzyme of PUFA synthesis, FADS1, which may indicate anti-inflammatory and antiarteriosclerotic effects. t10c12 CLA showed regulatory effects on various genes: lower expression levels of CA3 and IGF1 after t10c12 CLA treatment in the whole group could be a sign for a beginning insulin resistance. On the other hand, higher expression levels of SCD, a key enzyme of MUFA synthesis, lower expression of visfatin, the tendency towards higher levels of adiponectin and the reduction in CREB5 gene expression in rare allele carriers indicate beneficial effects of 10c12 CLA for this genotype.
The CLA mixture treatment caused significant genotype specific differences in expression of PPAR $\gamma$ and the PPAR dependent leptin gene. The fact that the CLA effect on expression of PPAR $\gamma$ and leptin genes depends on the PPAR $\gamma 2$ Pro12Ala polymorphism suggests that PPAR $\gamma 2$ contributes to regulatory effects of CLA. The results of the PPAR $\gamma$ dependent genes, however, do not show a uniform pattern and interfering factors like HPGD further diversified response to dietary intervention, reflecting the complexity of interacting regulators.

\section{Competing interests}

The authors JH, DR, RH, UH, MP, AA, CL, PW and SS declare that they have no competing interests.

DB is employee of Cognis $\mathrm{GmbH}$. JS received research support from Cognis $\mathrm{GmbH}$ for this and several other studies, JS gave a talk on CLA paid for by Cognis $\mathrm{GmbH}$

\section{Authors' contributions}

JH, DR, UH, MP, CL, PW and JS were responsible for the conception and design of the study, JH, UH, DR, CL, and PW for the conduct of the study; JH, DR, RR, MP, SS and PW for data acquisition; JH, RH and AA for statistical analysis; JH, DR, UH, RH and JS for data interpretation; JH and JS for drafting the manuscript; DR, UH, DB, CL, AA, MP and JS for critical revision; JS and DB for handling funding and supervision.

\section{References}

I. Park Y, Albright KJ, Liu W: Effect of conjugated linoleic acid on body composition in mice. Lipids 1997, 32:853-858.

2. Ryder JW, Portocarrero CP, Song XM, Cui L, Yu M, Combatsiaris T, Galuska D, Bauman DE, Barbano DM, Charron MJ, et al:: IsomerSpecific Antidiabetic Properties of Conjugated Linoleic Acid: Improved Glucose Tolerance, Skeletal Muscle Insulin Action, and UCP-2 Gene Expression. Diabetes 200I, 50:1149-1157.

3. Evans ME, Brown JM, Mclntosh MK: Isomer-specific effects of conjugated linoleic acid (CLA) on adiposity and lipid metabolism. J Nutr Biochem 2002, I 3:508-5 I6.

4. Whigham LD, Watras AC, Schoeller DA: Efficacy of conjugated linoleic acid for reducing fat mass: a meta-analysis in humans. Am J Clin Nutr 2007, 85: I 203-I2II.

5. Fajas L, Auboeuf D, Raspe E, Schoonjans K, Lefebvre A-M, Saladin R, Najib J, Laville M, Fruchart J-C, Deeb S, et al.: The Organization, Promoter Analysis, and Expression of the Human PPARgamma Gene. J Biol Chem 1997, 272:18779-18789.

6. Tonjes A, Scholz M, Loeffler M, Stumvoll M: Association of Prol 2Ala Polymorphism in Peroxisome Proliferator-Activated Receptor \{gamma\} With Pre-Diabetic Phenotypes: Meta-analysis of $\mathbf{5 7}$ studies on nondiabetic individuals. Diabetes Care 2006, 29:2489-2497.

7. Helwig U, Rubin D, Kiosz J, Schreiber S, Folsch UR, Nothnagel M, Doring F, Schrezenmeir J: The minor allele of the PPARgamma2 proI $2 \mathrm{Ala}$ polymorphism is associated with lower postprandial TAG and insulin levels in non-obese healthy men. $\mathrm{Br} J$ Nutr 2007, 97:847-854.

8. Ylonen SK, Salminen I, Lyssenko V, Virtanen SM, Groop L, Aro A, Saloranta C: The Prol2Ala polymorphism of the PPAR[gamma] 2 gene affects associations of fish intake and marine n-3 fatty acids with glucose metabolism. Eur J Clin Nutr 2007, 62:1432-1439.

9. Houseknecht KL, Heuvel JP Vanden, Moya-Camarena SY, Portocarrero $\mathrm{CP}$, Peck LW, Nickel KP, Belury MA: Dietary conjugated 
linoleic acid normalizes impaired glucose tolerance in the Zucker diabetic fatty fa/fa rat. Biochem Biophys Res Commun 1998, 244:678-682.

10. Nazare JA, de la Perriere AB, Bonnet F, Desage M, Peyrat J, Maitrepierre C, Louche-Pelissier C, Bruzeau J, Goudable J, Lassel T, et al.: Daily intake of conjugated linoleic acid-enriched yoghurts: effects on energy metabolism and adipose tissue gene expression in healthy subjects. Br J Nutr 2007, 97:273-280.

II. Helwig U, Rubin D, Kiosz J, Bitter W, Schreiber S, Doring F, Folsch UR, Schrezenmeir J: The effects of retinol on postprandial parameters in men with different FABP2 promoter haplotypes. Horm Metab Res 2007, 39:237-243.

12. Irizarry RA, Hobbs B, Collin F, Beazer-Barclay YD, Antonellis KJ, Scherf U, Speed TP: Exploration, normalization, and summaries of high density oligonucleotide array probe level data. Biostat 2003, 4:249-264.

13. Westfall PH, Young SS: P-value adjustments for multiple tests in multivariate binomial models. I Am Stat Assoc 1989, 84:780-786.

14. Wenzel JJ, Piehler A, Kaminski WE: ABC A-subclass proteins: gatekeepers of cellular phospho- and sphingolipid transport. Front Biosci 2007, I 2:3177-3193.

15. Piehler A, Kaminski WE, Wenzel J, Langmann T, Schmitz G: Molecular structure of a novel cholesterol-responsive $A$ subclass ABC transporter, ABCA9. Biochem Biophys Res Commun 2002, 295:408-4I6.

16. Yu-Poth S, Yin D, Zhao G, Kris-Etherton PM, Etherton TD: Conjugated Linoleic Acid Upregulates LDL Receptor Gene Expression in HepG2 Cells. J Nutr 2004, I 34:68-7I.

17. Degrace P, Demizieux L, Gresti J, Chardigny J-M, Sébédio J-L, Clouet P: Association of liver steatosis with lipid oversecretion and hypotriglyceridaemia in C57BL/6j mice fed trans-10,cis- I2linoleic acid. FEBS Lett 2003, 546:335-339.

18. Granlund L, Pedersen JI, Nebb HI: Impaired lipid accumulation by trans I0, cisI2 CLA during adipocyte differentiation is dependent on timing and length of treatment. Biochim Biophy Acta 2005, 1687: 1।-22.

19. Degrace P, Moindrot B, Mohamed I, Gresti J, Du Z-Y, Chardigny J-M, Sebedio J-L, Clouet $P$ : Upregulation of liver VLDL receptor and FAT/CD36 expression in LDLR-/- apoB I00/100 mice fed trans-10,cis-12 conjugated linoleic acid. J Lipid Res 2006, 47:2647-2655

20. Chen M, Yang YK, Loux TJ, Georgeson KE, Harmon CM: The role of hyperglycemia in FAT/CD36 expression and function. Pediatr Surg Int 2006, 22:647-654.

21. Yang YK, Chen M, Clements RH, Abrams GA, Aprahamian CJ, Harmon CM: Human mesenteric adipose tissue plays unique role versus subcutaneous and omental fat in obesity related diabetes. Cell Physiol Biochem 2008, 22:531-538.

22. Deeb SS, Fajas L, Nemoto M, Pihlajamaki J, Mykkanen L, Kuusisto J, Laakso M, Fujimoto W, Auwerx J: A Prol2Ala substitution in PPARgamma2 associated with decreased receptor activity, lower body mass index and improved insulin sensitivity. Nat Genet 1998, 20:284-287.

23. Deng T, Shan S, Li P-P, Shen Z-F, Lu X-P, Cheng J, Ning Z-Q: Peroxisome Proliferator-Activated Receptor-\{gamma\} Transcriptionally Up-Regulates Hormone-Sensitive Lipase via the Involvement of Specificity Protein-I. Endocrinology 2006, | 47:875-884.

24. Lasa A, Churruca I, Simon E, Fernandez-Quintela A, Rodriguez VM, Portillo MP: Trans- I 0, cis- I 2-conjugated linoleic acid does not increase body fat loss induced by energy restriction. $\mathrm{Br} J \mathrm{Nutr}$ 2008, I 00: 1245-1250.

25. Stanton LW, Ponte PA, Coleman RT, Snyder MA: Expression of CA III in rodent models of obesity. Mol Endocrinol I99I, 5:860-866.

26. Alver A, Uçar F, Keha EE, Kalay E, Ovali E: Effects of Leptin and Insulin on CA III Expression in Rat Adipose Tissue. J Enzyme Inhib Med Chem 2004, I 9:279-28I.

27. Wauters M, Considine RV, Van Gaal LF: Human leptin: from an adipocyte hormone to an endocrine mediator. Eur J Endocrinol 2000, I43:293-3II.

28. Claycombe KJ, Jones BH, Standridge MK, Guo Y, Chun JT, Taylor JW, Moustaid-Moussa N: Insulin increases fatty acid synthase gene transcription in human adipocytes. $\mathrm{Am} J$ Physiol 1998, 274:RI253-1259.
29. Berndt J, Kovacs P, Ruschke K, Kloting N, Fasshauer M, Schon MR, Korner $A$, Stumvoll $M$, Bluher $M$ : Fatty acid synthase gene expression in human adipose tissue: association with obesity and type 2 diabetes. Diabetologia 2007, 50:|472-|480.

30. Flowers MT, Ntambi JM: Stearoyl-CoA desaturase and its relation to high-carbohydrate diets and obesity. Biochim Biophys Acta 2009, I79 I:85-9|.

31. Kim Y-C, Ntambi JM: Regulation of Stearoyl-CoA Desaturase Genes: Role in Cellular Metabolism and Preadipocyte Differentiation. Biochem Biophys Res Commun 1999, 266: I-4

32. Brown JM, Boysen MS, Jensen SS, Morrison RF, Storkson J, Lea-Currie $R$, Pariza M, Mandrup S, Mclntosh MK: Isomer-specific regulation of metabolism and PPAR \{gamma\} signaling by CLA in human preadipocytes. J Lipid Res 2003, 44: I 287-1300.

33. Sjogren P, Sierra-Johnson J, Gertow K, Rosell M, Vessby B, de Faire $U$, Hamsten A, Hellenius ML, Fisher RM: Fatty acid desaturases in human adipose tissue: relationships between gene expression, desaturation indexes and insulin resistance. Diabetologia 2008, 5 I :328-335.

34. Yao-Borengasser A, Rassouli N, Varma V, Bodles AM, Rasouli N, Unal R, Phanavanh B, Ranganathan G, McGehee RE Jr, Kern PA: StearoylCoenzyme A Desaturase I Gene Expression Increases after Pioglitazone Treatment and Is Associated with Peroxisomal Proliferator-Activated Receptor-\{gamma\} Responsiveness. J Clin Endocrinol Metab 2008, 93:4431-4439.

35. Schmitz-Peiffer C, Craig DL, Biden TJ: Ceramide Generation Is Sufficient to Account for the Inhibition of the Insulin-stimulated PKB Pathway in C2CI2 Skeletal Muscle Cells Pretreated with Palmitate. J Biol Chem 1999, 274:24202-24210.

36. Mangravite LM, Dawson K, Davis RR, Gregg JP, Krauss RM: Fatty acid desaturase regulation in adipose tissue by dietary composition is independent of weight loss and is correlated with the plasma triacylglycerol response. Am J Clin Nutr 2007, 86:759-767.

37. Steffen LM, Vessby B, Jacobs DR Jr, Steinberger J, Moran A, Hong CP, Sinaiko AR: Serum phospholipid and cholesteryl ester fatty acids and estimated desaturase activities are related to overweight and cardiovascular risk factors in adolescents. Int J Obes 2008, 32:1297-1304.

38. Chung S, Brown JM, Provo JN, Hopkins R, Mclntosh MK: Conjugated Linoleic Acid Promotes Human Adipocyte Insulin Resistance through NF\{kappa\}B-dependent Cytokine Production. J Biol Chem 2005, 280:38445-38456.

39. Bays H, Mandarino L, DeFronzo RA: Role of the Adipocyte, Free Fatty Acids, and Ectopic Fat in Pathogenesis of Type 2 Diabetes Mellitus: Peroxisomal Proliferator-Activated Receptor Agonists Provide a Rational Therapeutic Approach. J Clin Endocrinol Metab 2004, 89:463-478.

40. Whigham LD, Watras AC, Schoeller DA: Efficacy of conjugated linoleic acid for reducing fat mass: a meta-analysis in humans. Am J Clin Nutr 2007, 85: | 203-121I.

4I. Thrush AB, Chabowski A, Heigenhauser GJ, McBride BW, Or-Rashid $M$, Dyck DJ: Conjugated linoleic acid increases skeletal muscle ceramide content and decreases insulin sensitivity in overweight, non-diabetic humans. Appl Physiol Nutr Metab 2007, 32:372-382.

42. Riserus U, Vessby B, Arnlov J, Basu S: Effects of cis-9,trans-I I conjugated linoleic acid supplementation on insulin sensitivity, lipid peroxidation, and proinflammatory markers in obese men. Am J Clin Nutr 2004, 80:279-283.

43. Kennedy A, Chung S, LaPoint K, Fabiyi O, Mclntosh MK: Trans- I O, Cis-12 Conjugated Linoleic Acid Antagonizes LigandDependent PPAR\{gamma\} Activity in Primary Cultures of Human Adipocytes. J Nutr 2008, I 38:455-46I.

44. Miller JR, Siripurkpong P, Hawes J, Majdalawieh A, Ro H-S, McLeod RS: The trans-I0, cis-I 2 isomer of conjugated linoleic acid decreases adiponectin assembly by PPAR \{gamma\}-dependent and PPAR\{gamma\}-independent mechanisms. J Lipid Res 2008, 49:550-562.

45. Nakamura YK, Omaye ST: Conjugated linoleic acid isomers' roles in the regulation of PPAR-[gamma] and NF-[kappa]B DNA binding and subsequent expression of antioxidant enzymes in human umbilical vein endothelial cells. Nutrition 2009, 25:800-8II.

46. Clement L, Poirier H, Niot I, Bocher V, Guerre-Millo M, Krief S, Staels $B$, Besnard P: Dietary trans- I0,cis- I 2 conjugated linoleic acid 
induces hyperinsulinemia and fatty liver in the mouse. J Lipid Res 2002, 43:1400-1409.

47. Yang B, Hodgkinson AD, Oates PJ, Kwon HM, Millward BA, Demaine AG: Elevated Activity of Transcription Factor Nuclear Factor of Activated T-Cells 5 (NFAT5) and Diabetic Nephropathy. Diabetes 2006, 55: | 450-I 455.

48. Shimizu H, Ohtani KI, Tsuchiya T, Sato N, Tanaka Y, Takahashi H, Uehara $Y$, Inukai T, Mori M: Aldose reductase mRNA expression is associated with rapid development of diabetic microangiopathy in Japanese Type 2 diabetic (T2DM) patients. Diabetes Nutr Metab 2000, 13:75-79.

49. Mayr B, Montminy M: Transcriptional regulation by the phosphorylation-dependent factor CREB. Nat Rev Mol Cell Biol 200I, 2:599-609.

50. Bouchard L, Tchernof A, Deshaies Y, Marceau S, Lescelleur O, Biron S, Vohl MC: ZFP36: a Promising Candidate Gene for ObesityRelated Metabolic Complications Identified by Converging Genomics. Obesity Surgery 2007, 17:372-382.

5I. Granlund L, Pedersen JI, Nebb HI: Impaired lipid accumulation by trans 10 , cis 12 CLA during adipocyte differentiation is dependent on timing and length of treatment. Biochim Biophys Acta 2005, 1687:1 I-22.

52. Zhou Y-T, Shimabukuro M, Koyama K, Lee Y, Wang M-Y, Trieu F, Newgard CB, Unger RH: Induction by leptin of uncoupling protein-2 and enzymes of fatty acid oxidation. Proc Natl Acad Sci USA 1997, 94:6386-6390.

53. Yamagishi S-i, Edelstein D, Du X-I, Kaneda Y, Guzman M, Brownlee M: Leptin Induces Mitochondrial Superoxide Production and Monocyte Chemoattractant Protein-I Expression in Aortic Endothelial Cells by Increasing Fatty Acid Oxidation via Protein Kinase A. J Biol Chem 200I, 276:25096-25I00.

54. Considine RV, Sinha MK, Heiman ML, Kriauciunas A, Stephens TW, Nyce MR, Ohannesian JP, Marco CC, McKee LJ, Bauer TL, Caro JF: Serum Immunoreactive-Leptin Concentrations in NormalWeight and Obese Humans. N Engl J Med 1996, 334:292-295

55. Korda M, Kubant R, Patton S, Malinski T: Leptin-induced endothelial dysfunction in obesity. Am J Physiol Heart Circ Physiol 2008, 295:HI5I4-I52I.

56. Singh P, Hoffmann M, Wolk R, Shamsuzzaman ASM, Somers VK: Leptin Induces C-Reactive Protein Expression in Vascular Endothelial Cells. Arterioscler Thromb Vasc Biol 2007, 27:e302-307.

57. Prais Botelho A, Santos-Zago LF, Costa de Oliveira A: Conjugated linoleic acid supplementation modified the body composition and serum leptin levels in weaning rats. Arch Latinoam Nutr 2008, 58:156-163.

58. Mousavinasab F, Tähtinen T, Jokelainen J, Koskela P, Vanhala M, Oikarinen J, Keinänen-Kiukaanniemi S, Laakso M: Common polymorphisms in the PPAR[gamma]2 and IRS-I genes and their interaction influence serum adiponectin concentration in young Finnish men. Mol Genet Metab 2005, 84:344-348.

59. Takata N, Awata T, Inukai K, Watanabe M, Ohkubo T, Kurihara S, Inaba M, Katayama S: Prol 2Ala substitution in peroxisome proliferator-activated receptor [gamma] 2 is associated with low adiponectin concentrations in young Japanese men. Metabolism 2004, 53:1548.

60. McFarlin BK, Strohacker KA, Kueht ML: Pomegranate seed oil consumption during a period of high-fat feeding reduces weight gain and reduces type 2 diabetes risk in CD-I mice. Br J Nutr 2009, 102:54-59.

61. Dogru T, Sonmez A, Tasci I, Bozoglu E, Yilmaz MI, Genc H, Erdem G, Gok M, Bingol N, Kilic S, et al.: Plasma visfatin levels in patients with newly diagnosed and untreated type 2 diabetes mellitus and impaired glucose tolerance. Diabetes Res Clin Pract 2007, 76:24-29.

62. Pfutzner A, Marx N, Walcher D, Lobig M, Seidel D, Forst T: Impact of rosiglitazone on visfatin and adiponectin plasma concentrations in patients with type 2 diabetes and coronary artery disease. Clin Lab 2008, 54:237-241.

63. Hammarstedt A, Pihlajamaki J, Rotter Sopasakis V, Gogg S, Jansson PA, Laakso M, Smith U: Visfatin Is an Adipokine, But It Is Not Regulated by Thiazolidinediones. J Clin Endocrinol Metab 2006, 91:II8I-II84

64. Varma V, Yao-Borengasser A, Bodles AM, Rasouli N, Phanavanh B, Nolen GT, Kern EM, Nagarajan R, Spencer HJ III, Lee M-J, et al.: Thrombospondin-I Is an Adipokine Associated With Obes- ity, Adipose Inflammation, and Insulin Resistance. Diabetes 2008, 57:432-439.

65. Huang H, Campbell SC, Bedford DF, Nelius T, Veliceasa D, Shroff EH, Henkin J, Schneider A, Bouck N, Volpert OV: Peroxisome Proliferator-Activated Receptor \{gamma\} Ligands Improve the Antitumor Efficacy of Thrombospondin Peptide ABT5I0. Mol Cancer Res 2004, 2:54 I-550.

66. Kim EJ, Kang I-J, Cho HJ, Kim WK, Ha Y-L, Park JHY: Conjugated Linoleic Acid Downregulates Insulin-Like Growth Factor-I Receptor Levels in HT-29 Human Colon Cancer Cells. J Nutr 2003, 133:2675-268।

67. Hussain MA, Schmitz O, Mengel A, Keller A, Christiansen JS, Zapf J, Froesch ER: Insulin-like growth factor I stimulates lipid oxidation, reduces protein oxidation, and enhances insulin sensitivity in humans. J Clin Invest 1993, 92:2249-2256.

68. Marin P, Kvist H, Lindstedt G, Sjostrom L, Bjorntorp P: Low concentrations of insulin-like growth factor-l in abdominal obesity. Int J Obes Relat Metab Disord 1993, I 7:83-89.

69. Rasmussen MH, Frystyk J, Andersen T, Breum L, Christiansen JS, Hilsted J: The impact of obesity, fat distribution, and energy restriction on insulin-like growth factor-I (IGF-I), IGF-binding protein-3, insulin, and growth hormone. Metabolism 1994, 43:3I5-3I9.

70. Moloney F, Toomey S, Noone E, Nugent A, Allan B, Loscher CE, Roche HM: Antidiabetic Effects of cis-9, trans-I I-Conjugated Linoleic Acid May Be Mediated via Anti-Inflammatory Effects in White Adipose Tissue. Diabetes 2007, 56:574-582.

7I. Riserus U, Vessby B, Arnlov J, Basu S: Effects of cis-9,trans- I I conjugated linoleic acid supplementation on insulin sensitivity, lipid peroxidation, and proinflammatory markers in obese men. Am J Clin Nutr 2004, 80:279-283.

72. Riserus $U$, Arner P, Brismar K, Vessby B: Treatment with dietary trans I 0 cis 12 conjugated linoleic acid causes isomer-specific insulin resistance in obese men with the metabolic syndrome. Diabetes Care 2002, 25:1516-1521.

73. Ribon V, Printen JA, Hoffman NG, Kay BK, Saltiel AR: A Novel, Multifunctional c-Cbl Binding Protein in Insulin Receptor Signaling in 3T3-LI Adipocytes. Mol Cell Biol 1998, 18:872-879.

74. Ribon V, Johnson JH, Camp HS, Saltiel AR: Thiazolidinediones and insulin resistance: Peroxisome proliferatoractivated receptor gamma activation stimulates expression of the CAP gene. Proc Natl Acad Sci USA 1998, 95: | 1475 I- I4756.

75. Ueki K, Algenstaedt P, Mauvais-Jarvis F, Kahn CR: Positive and Negative Regulation of Phosphoinositide 3-Kinase-Dependent Signaling Pathways by Three Different Gene Products of the p85alpha Regulatory Subunit. Mol Cell Biol 2000, 20:8035-8046.

76. Shepherd PR, Withers DJ, Siddle K: Phosphoinositide 3-kinase: the key switch mechanism in insulin signalling. Biochem J 1998, 333:47I-490.

77. Chou W-L, Chuang L-M, Chou C-C, Wang AHJ, Lawson JA, FitzGerald GA, Chang Z-F: Identification of a Novel Prostaglandin Reductase Reveals the Involvement of Prostaglandin E2 Catabolism in Regulation of Peroxisome Proliferator-activated Receptor \{gamma\} Activation. J Biol Chem 2007, 282:18162-18172.

78. Rega G, Kaun C, Weiss TW, Demyanets S, Zorn G, Kastl SP, Steiner S, Seidinger D, Kopp CW, Frey M, et al: Inflammatory Cytokines Interleukin-6 and Oncostatin M Induce Plasminogen Activator Inhibitor-I in Human Adipose Tissue. Circulation 2005, I I I:1938-1945

79. Camirand A, Marie V, Rabelo R, Silva JE: Thiazolidinediones Stimulate Uncoupling Protein-2 Expression in Cell Lines Representing White and Brown Adipose Tissues and Skeletal Muscle. Endocrinology 1998, 139:428-431.

80. Chevillotte E, Giralt M, Miroux B, Ricquier D, Villarroya F: Uncoupling Protein-2 Controls Adiponectin Gene Expression in Adipose Tissue Through the Modulation of Reactive Oxygen Species Production. Diabetes 2007, 56:1042-1050.

8I. Lantner F, Starlets D, Gore Y, Flaishon L, Yamit-Hezi A, Dikstein R, Leng L, Bucala R, Machluf $Y$, Oren M, Shachar I: CD74 induces TAp63 expression leading to B-cell survival. Blood 2007, I I0:4303-43| I.

82. Morris EJ, Michaud WA, Ji JY, Moon NS, Rocco JW, Dyson NJ: Functional identification of Api5 as a suppressor of E2F-dependent apoptosis in vivo. PLoS Genet 2006, 2:el 96. 
83. Bhattacharya A, Banu J, Rahman M, Causey J, Fernandes G: Biological effects of conjugated linoleic acids in health and disease. J Nutr Biochem 2006, 17:789-810.

84. Murphy EF, Hooiveld G], Muller M, Calogero RA, Cashman KD: Conjugated Linoleic Acid Alters Global Gene Expression in Human Intestinal-Like Caco-2 Cells in an Isomer-Specific Manner. J Nutr 2007, 137:2359-2365.

85. Yu S, Matsusue K, Kashireddy P, Cao W-Q, Yeldandi V, Yeldandi AV, Rao MS, Gonzalez FJ, Reddy JK: Adipocyte-specific Gene Expression and Adipogenic Steatosis in the Mouse Liver Due to Peroxisome Proliferator-activated Receptor gamma I (PPARgamma I) Overexpression. I Biol Chem 2003, 278:498-505.

86. Tontonoz P, Nagy L, Alvarez JG, Thomazy VA, Evans RM: PPARgamma promotes monocyte/macrophage differentiation and uptake of oxidized LDL. Cell 1998, 93:24I-252.

87. Way JM, Harrington WW, Brown KK, Gottschalk WK, Sundseth SS, Mansfield TA, Ramachandran RK, Willson TM, Kliewer SA: Comprehensive Messenger Ribonucleic Acid Profiling Reveals That Peroxisome Proliferator-Activated Receptor \{\{gamma\} Activation Has Coordinate Effects on Gene Expression in Multiple Insulin-Sensitive Tissues. Endocrinology 2001, I 42: $1269-1277$

88. Zhang L, Ge L, Tran T, Stenn K, Prouty SM: Isolation and characterization of the human stearoyl-CoA desaturase gene promoter: requirement of a conserved CCAAT cis-element. Biochem J 200I, 357:183-193.

89. Jimenez MA, Akerblad P, Sigvardsson M, Rosen ED: Critical Role for Ebfl and Ebf2 in the Adipogenic Transcriptional Cascade. Mol Cell Biol 2007, 27:743-757.

90. Iwaki M, Matsuda M, Maeda N, Funahashi T, Matsuzawa Y, Makishima M, Shimomura I: Induction of Adiponectin, a Fat-Derived Antidiabetic and Antiatherogenic Factor, by Nuclear Receptors. Diabetes 2003, 52:1655-1663.

91. Riera-Guardia N, Rothenbacher D: The effect of thiazolidinediones on adiponectin serum level: a meta-analysis. Diabetes Obes Metab 2008, 10:367-375.

92. Hollenberg AN, Susulic VS, Madura JP, Zhang B, Moller DE, Tontonoz P, Sarraf P, Spiegelman BM, Lowell BB: Functional Antagonism between CCAAT/Enhancer Binding Protein-alpha and Peroxisome Proliferator-activated Receptor-gamma on the Leptin Promoter. J Biol Chem 1997, 272:5283-5290.

93. Qin X, Shen H, Liu M, Yang Q, Zheng S, Sabo M, D'Alessio DA, Tso $P$ : GLP-I reduces intestinal lymph flow, triglyceride absorption, and apolipoprotein production in rats. Am JPhysiol Gastrointest Liver Physiol 2005, 288:943-949.

94. Armoni M, Kritz N, Harel C, Bar-Yoseph F, Chen H, Quon MJ, Karnieli E: Peroxisome Proliferator-activated Receptor-\{gamma\} represses GLUT4 promoter activity in primary adipocytes, and rosiglitazone alleviates this effect. J Biol Chem 2003, 278:306|4-30623.

95. Standaert ML, Kanoh Y, Sajan MP, Bandyopadhyay G, Farese RV: Cbl, IRS-I, and IRS-2 Mediate Effects of Rosiglitazone on PI3K, PKC-\{lambda\}, and Glucose Transport in 3T3/LI Adipocytes. Endocrinology 2002, I43:1705-1716.
Publish with Biomed Central and every scientist can read your work free of charge

"BioMed Central will be the most significant development for disseminating the results of biomedical research in our lifetime. "

Sir Paul Nurse, Cancer Research UK

Your research papers will be:

- available free of charge to the entire biomedical community

- peer reviewed and published immediately upon acceptance

- cited in PubMed and archived on PubMed Central

- yours - you keep the copyright
BioMedcentral 